and eyes to the side opposite to the abscess may occur, and would be explained by pressure on the side of the pons adjacent to the abscess and irritation of the motor tracks to the affected muscles above the decussation of the pyramids. Paralysis of cranial nerves, when brain abscess has been diagnosed from other evidence, is a distinct point in favour of its being situated in the cerebellam rather than in the temporo-sphenoidal lobe, since it is usually due to pressure or local meningitis, which is obviously more likely to extend to these nerves from the cerebellum than from the more distant temporo-sphenoidal lobe. The sluggishness of the pupils in some cases, and their complete paralysis with dilatafion in others, must be referred ratber to general increase of intracranial pressure or to optic atrophy than to local lesions of the third nerves. Dr. Risien Russell, after ablation of one cerebellar hemisphere in animals, noted skew deviation of the eyes and proptosis. Something a little resembling this oscurred in the writer's case of cerebellar abscess. The skew deviation, however, was not complete, since, although the eye on the side of the lesion deviated upwards, the opposite eye did not appear to deviate downwards. The proptosis also was noted only on the side of the lesion and may have been only apparent owing to the slight widening of the palpebral fissure which was aiso present. In Dr. Risien Russell's animals, moreover, both phenomena were transitory.

Paralysis of the limbs from pressure on some part of the motor track occurs of tener in the case of temporo-sphenoidal than of cerebellar abscess, but is not common in either. The only example I have been able to find in a cerebellar abscess is the paralysis of the arm on the same side as the abscezs. The diagnostic value of such a symptom is obvious, since in the absence of a second lesion on the opposite side it clearly points to pressure on the pons or medulla below the decussation of the motor paths.

The method of operating adopted by Dr. Macewen in all his cases was to first open the mastoid antrum and to carefully examine the adjacent parts by enlarging the opening as cccasion required. He has shown, and anyone may easily verify his statements on a skull, that in this way it is quite practicable to examine, not merely the middle ear, mastoid antrum, and cells, bat also the tegmen tympani and the lateral sinus. In this way he has followed $\mathrm{pp}$ the local extensions of the disease either forwards and upwards throngh the tegmen tympani into the temporo-sphenoidal lobe, or backwards to the sigmoid sinus or cerebellar fossa. The affected parts of the temporo-sphenoidal lobe or cere bellum can not only be examined in this way, but an abscess in either situation can be evacuated and drained throagh the open mastoid antram. In most cases, however, Dr. Macewen, after following the disease from its origin to either the brain or cerebellnm, makes a second opening for drainage directly over the affected part : in the case of the brain, by a trephine opening just above the auditory meatus, and for the cerebellum by an opening just behind and below the curve of the lateral sinns. In the extremely complicated cases with which Dr. Macewen had to deal, it cannot be doubted that this procedure was the best which could have been adopted. Pent-up matter in the middle ear or mastoid, extra dural abscess, thrombosis of the lateral sinus, and abscess of either the brain or cerebellam may all be present in a single case ; and in this way they may all be followed up and dealt with from one opening in the bone, and there is no possibility of overlooking any important complication. Al brain abscesses are, however, not of this complicated character. In many cases a single abscess in the brain or cerebellam is the only important lesion, the ear disease which gave rise to it being so slight as to require no opera tive interference or being, at any rate, of entirely subordinate importance. The case now reported is a good example of this kind, but nearly one half of the cases which I have analysed were almost equally uncompicated. In such cases I believe the operation devised and carried out by $\mathrm{Mr}$. Percy Dean, which was followed in my case, is by far the best procedure to adopt. This single trephine opening immediately over the lateral sinus not only enables the latter to be examined and, if necessary, dealt with, but enables one with the greatest ease and expedition to explore either the cerebellum or temporo-sphenoidal lobe, or both. The value of this fact, in view of the frequent absence of any localising indications, is obvious. When the brain abscess has been dealt with the antrum may not require to be opened, or if it does it may be safely deferred to a later time, after the more pressing complication has been relieved.
Bibliagraphy.-Macewen : Pyogenic Infective Diseases of the Brain and Spinal Cord. Ballance : Clinical Journal, 1893. Dean : THE LAwCET, July 30th, 1892. Bickersteth : Brit. Mled. Jour., vol. i. 1893. C. E. Harrison, THE LAxCET, Oct. 1st, 1892. Koch : Brit. Med. Jour., December, 1893. Milligan and Hare: Brit. Med. Jour., vol. i. 1890. Bryden : Brit. Med. Jour., vol. i. 1890. McMurray : THE LANCET, July 23rd, 1887. Hadden : Brit. Med. Jour., vol. i. 1884.

\section{PAPILLOMA OF THE SEPTUM NASI IN A MAN AGED EIGHTY-TWO YEARS, COM- PLICATED WITH RODENT ULCER OF THE NOSE; SOME REMARKS ON NASAL PAPILLOMATA.}

BY PHILIP R. W. DE SANTI, F.R.C.S. ENG., I R.C P. LOND.,

SURGICAL REGISTRAR TO WESTMINSTER HOSPITAL MEDICAL SCHOOL, SENLOR CLINICAL ASSISTANT THROAT AND NOSE DEPARTMENT, WESTMINSTER HOSPITAX.

ON June 8th, 1894, a man eighty-two years of age was admitted into St. Matthew Ward, Westminster Hospital, under Mr. Cowell, suffering from a papillomatous growth occupying the left anterior nares and originating from the septum nasi. He presented, also, on the external surface of the nose on the right side a small rodent ulcer. The case seems to me worth recording-firstly, on account of the rarity of true papilloma nasi ; secondly, on account of the plurality of neoplasms ; and, thirdly, because of the rarity of a benign growth starting into existence at so old an age. I have to record my best thanks to $\mathrm{Mr}$. Cowell for permission to publish the case.

A little over five years ago the patient noticed a small pimple on the inner and upper part of the left nostril which very gradually increased in size. He had never had any pain in it, but had had a few attacks of slight epistaxis from that nostril. During the last year the growth had grown more rapidly and now occupied the whole of the left anterior nares. About a year ago he noticed a disagreeable smell emanating from it and there was an occasional foul discharge from the nostril. This smell was also noticed by other people. He came to the hospital on account of the inconvenience caused by the blocking of the left nares and consequent obstruction to nasal breathing, and the protrusion of the growth and occasional discharge. The patient is an exceedingly hale old man of particalarly bright intellect. $\mathrm{He}$ is in very good general health and has not been losing flesh. His family history is good. He has never had any nasal or throat trouble before. There is no history or evidence of syphilis. About a year ago he noticed a small hard pimple on the external surface of the right side of the nose; it irritated him, and he consequently used to scratch it frequently; it became ulcerated, and has very gradually extended in area ; it has caused him no pain. He is quite certain that there was no pimple or ulcerated surface there before a year ago. On examination of the patient it was noticed that the left anterior nares was occupied by a large darkish mass distinctly protruaing from the nasal cavity, and causing marked dilatation of that side. On examining with the finger it was found that the tumour was freely movable; that it entirely blocked the left anterior nares, and that it could by gentle palling be withdrawn to a considerable extent from the nostril ; it was pear-shaped, distinctly pedunculated, and soft to the touch, but not friable. The naked-eye appearance of the neoplasm was as follows. It was a very markedly papillated growth, the part extruded from the nostril being covered with $a$ thin blackish crust, and that contained within the nares being of a moderately pink colour; the tumour was made ap of small branched processes, subdividing again and again, and connected with the parent tissue by small narrow stalks, the whole resembling a miniature caulitower in appearance. Its size was that of an ordinary walnut. By gently pulling on the growth and holding it to one side and passing a nasal speculum (the growth could be pulled sufficiently far to one side and out of the nostril to permit of the use of the nasal speculum) the peduncle could with ease be traced up to its attachment at the upper and anterior part of the septum, 
close to the junction of bone and cartilage ; the peduncle was very distinct, long and thin, and the surface of the bony septum where it was attached looked healthy, and was in no way infiltrated or "stiff." There was no pain or hæmorrhage on manipulation, and a probe conld be passed round the peduncle. The rest of the nasal cavity was healthy, there being no other growths : the nasopharynx, pharynx, and larynx were normal. There were no enlarged glands, submaxillary or otherwise. On examination of the external surface of the nose a small hard oval ulcer covered with a brownish scab was found occupying the borderland of nose and cheek and on a level with the lower border of the nasal bone of the right side : it was about the size of a threepenny piece, flattened and irregular, with slightly raised and indurated edges, and discharged a little watery fluid under the scab. It was painless, and there were no enlarged glands.

The intra-nasal tumour was diagnosed as a true papilloma on the following grounds: the very slow growth of the tumour - namely, over five years; the absence of pain, friability or frequent and severe hæmorrhage, the pedunculated appearance, free mobility, and want of any infiltration at its attichment to the septum, the absence of glandular enlargement and ulceration, and the general good health of the patient. Throwing some doubt on the diagnosis of benign tumour were: (1) the seat of origin of the growth, many authorities holding that any growth springing from the septum nasi should be looked upon with very grave suspicion, Plicque I going so far as to say, "A polypus inserted on the septum must, in fact, always be regarded as of malignant nature"; (2) the increased rapidity of growth within the last few months; (3) the age of the patient; (4) the presence of a malignant growth-rodent ulcer on the external surface of the nose. It was possible that the neoplasm originally benign was becoming malignant in character. The growth was removed on June 19th, the peduncle being snipped across with scissors as close as possible to its attachment to the septum, and the cut surface cauterised. There was scarcely any bleeding. The nostril was packed with strips of iodoform gauze. No anæsthetic, general or local, was employed. The growth measured $1 \frac{1}{4}$ in. in length and $2 \frac{1}{2}$ in. in circumference. Microscopic sections were ent and examined by $\mathrm{Dr}$. Hebb, pathologist to the Westminster Hospital, and he kindly reported to me that the nature of the growth was benign and that of a true papilloma. I append a drawing of the

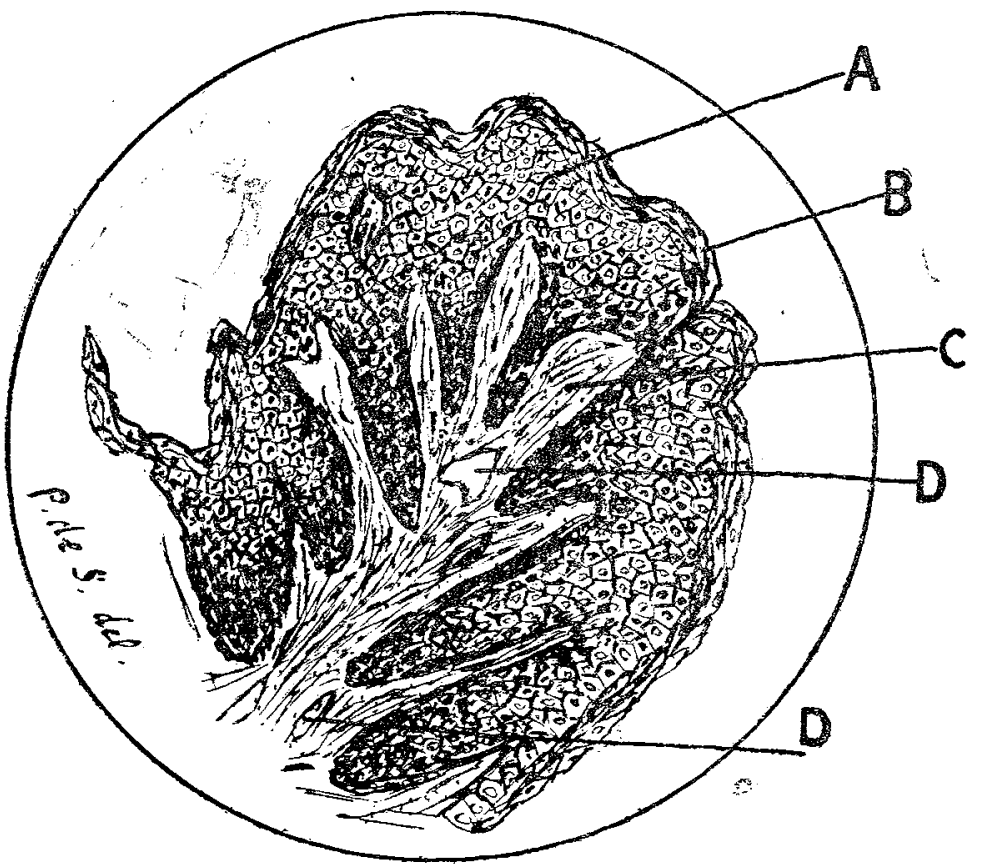

microscopic appearance of the growth. It will be seen that it consists of a stroma (c), which forms branching processes extending towards the free surface and consisting of fibrous tissue in small quantity, and bloodressels (D); that the surface of the stroma is covered with several layers of epithelium (A), the most superficial being flattened squamous cells (B). There is no small cell infiltration of the base of the growth, or ingrowths of epithelinm. I have already enumerated the main points that were considered in the diagnosis; but, though clinically and microscopically the evidence is in favour of the growth being innocent, I canno say that in my own mind I feel quite satisfied as to its nor malignant nature. The very late age-namely, seventy seven - at which the growth first started is very suspicious. Surely it is very uncommon for a simple papilloma to start into existence so late in life. The site of origin also is much in favour of malignancy, though I certainly would not go so far as Plicque, ${ }^{2}$ who regards any polypus growing from the septum as malignant. There is $n$ doubt that perfectly innocent tumours, papillomatous anc otherwise, do grow from the septum nasi, and many such cases have been recorded, though generally in young patients. Taking, therefore, into consideration the great age of the patient, the seat of origin of the tamour, its increased rapidity of growth, and the presence of a rodent ulcer on the nose, I question whether the macroscopic and microscopic appearances favouring non-malignancy are not thereby more than neutralised.

If the literature on the subject of nasal papilloma be consulted it is found that the disease is in the experience of most authorities very rare. Hopmann ${ }^{3}$ states that he met with papillomata in 14 cases out of 100 of nasal polypi, and always on the inferior turbinate bones; Schaeffer 20 times in 182 cases of intra-nasal polypus. Both these authors, however, seem to have included in their cases tumours which were by no means true papillomata, such as pedunculated papillary sarcomata, angiomata, and adenomata, the number of true papillomata being very small indeed. Ingals ${ }^{4}$ reported a case under his care of warty growth springing from the septum within about $1 \frac{1}{2}$ centimetres of the nostril, and measuring about $7 \mathrm{c.m}$. in diameter by $17 \mathrm{~mm}$. in length, and with a base as large as the diameter of the growth. It was removed with the snare and the base cauterised with chromic acid. Within a week, two or three small warty growths appeared on the floor of the nostril and the anterior end of the inferior turbinate bone, and others later, on the septum. Altogether there were many recurrences of similar growths, at least twenty-five to thirty being removed at intervals, Microscopic examination proved the growths to be papillomata. The patient was eventually quite cured. Ingals also mentions a case of warty growth, growing from the septum in an elderly lady, which he successfully removed, and which did not recur. These were the only two cases of the disease he had met with. Jarvis met with two cases only in his practice and in neither case did he consider the growths to be true papillomata, one being in his opinion a teleangeiectatic poly pus, the other an epithelioma which at first resembled a benign rrowth. J. Wright" states: "Out of several hundred nasa" tumours and hypertrophies removed, it has been my fortune to see but one case of what I regard as nasal papilloma." In his case the growth was the size of a split pea, and grew from the septum. Delavan states also that true papilloma in the nasal fossw is a rare disease. Butlin ${ }^{6}$ reported a case of papilloma of the septum occurring in a girl thirteen years of age, which hung down from the upper part of the front of the iaares, nearly blocking the passage, and which was successEully removed with the galvano-cautery, and did not recur. [ts microscopic appearance was that of a true papilloma. Moure ${ }^{7}$ also agrees that nasal papillomata are very rare. 'Two cases occurred in his clinic which to the naked eye could not be distinguished from papillomata, but which, when examined microscopically, were found to consist of granula lion tissue and hypertrophied mucous membrane.

Noquet ${ }^{8}$ reported a case of true papilloma, and also an account of another case which he took to be of the same nature; the microscopic appearance of the latter, however, showed mucous tissue covered by cylindrica: epithelium developed in the form of papillary projectiions. Mackenzie ${ }^{9}$ says they are of infrequent occurrence and generally situated on the inner surface of the alx nasi and in children. He met with only five cases of what he regarded as true papilloma. Wright ${ }^{10}$ mentions as additional published cases those of Michel ${ }^{11}$ and Zuckerkandl. ${ }^{12}$ In both

\footnotetext{
2 Ibid.

3 Archiv für Pathologische Anatomie und Physiologie und fur Klinische Medicin, No. 93,1883, p. 213.

4 Transactions of the American Laryngological Association, 1889, p. 64。 5 Ibid., 1891, p. 44. St. Bartholomew's Hospital Reports, vol. xxi., 1885 8 Revue de Laryngologie, June ist, 1891, No p. 324. Revue de Laryngologie, June lst, 1891, No. 11, p. 339

10 Transactions of the American Laryngological Association, 1891 p. 52.

11 Krankheiten der Nasenhöhle, p. 72
} 
chese authors' cases there was no microscopic examination. Aysaguer ${ }^{13}$ mentions two cases, but also unconfirmed by microscopic examination. Verneuil ${ }^{14}$ mentions one case, Cozzolino ${ }^{15}$ two cases, but not examined microscopically Nuthall, of St. Louis, one case of true papilloma; Solis Cohen ${ }^{16}$ one case with a similar growth in the larynx. Bosworth, in his book on "Diseases of the Nose and Throat," states that he only met with one case out of 200 intra-nasal orowths. McBride ${ }^{17}$ speaks of tumours occurring on the inferior turbinate bones, septam and floor of the nostril, and characterised by their papillary appearance. He treated a case in which masses of tissue of this nature grew from the floor and adjacent septum, and which when examined microscopically showed the structure of a soft fibroma.

There is no doubt that some confusion has been caused by the publication of several cases of nasal papillomata which, on further inquiry and examination, especially microscopically, have been proved to be of a quite different nature. The cases mentioned by Hopmann as papillomata were mostiy hypertrophies of the tissue of the turbinate bones, and indeed most of the so-called papillomata of the inferior turbinates are papillary hypertrophies of the erectile tissue of these bodies. Microscopically the gland tissue and bloodressels are found to be dilated, the epithelial covering proliferated, and the papillary processes become venous-like sinuses. This glandalar and vascular development is very marked and differs altogether histologically from true papilloma. The term true papilloma (papillary fibroma, dendritic vegetations, have been suggested as better terms) in my opinion, should be limited to a growth composed of numerous papillary processes, single and undivided, or branched and giving off processes which again in their turn bifurcate, with a stroma which is fibrous, small in quantity, sonetimes cellular, at other times dense, more or less vascular and with the surface invested by epithelium which is arranged in several layers. The epithelium, however much proliferated, should be quite distinct and defined from the connective tissue, and there should be no separate ingrowths of epithelium and no smal cell infiltration of the deeper tissues. The greatest importance should be attached to the condition of the basement membrane or parenchyma of the tumour. Virchow especially points out the importance of a sharp definition between the proliferated epithelium and the connective tissue, as a distinguishing point between papilloma and epithelioma. The microscopic section already referred to shows well the kind of epithelial cells lining the papillw, their numerous layers, the stroma, its fibrous nature and sharp definition from the proliferated epithelium.

Having determined upon what should be meant by a true papilloma nasi, pathologically and microscopically, a few words may be said as to its diagnosis clinically. The clinical symptoms and appearances of these growths are often most deceptive, it being often impossible to come to a conclusion without a microscopic examination. Especially do the papillary hypertrophies of the inferior turbinates simulate papilloma; and, as instancing this, I would again refer to the two cases of Moure, which had every aspect of papilIoma to the naked eye and clinically, but which on microscopic examination proved to be hypertrophied mucous membrane and granulation tissue; also to Noquet's similar case. True papilloma usually starts at the ala nasi, or the anterior and upper part of the septum, and, as a rule, occurs in young people. It grows slowly, is fairly firm in consistence, does not bleed excessively, though very fairly vascular, causes no glandular enlargement, is pedunculated rather than sessile, is asually freely movable and does not implicate the skin or surrounding tissues; it is sometimes multiple, and, if thoroughly removed, does not recur. Malignant growths (epithelioma and sarcoma), on the other hand, may start from any part of the nasal cavities, are often soft and friable, and grow very rapidly, with pain increasing as the growth extends. They canse frequent and severe hæmorrhage, alcerate, and implicate the surrounding tissues, are generally sessile, though a sarcoma may be pedunculated, are single, and sooner or later implicate the lymphatic glands. As to age, epithelioma occurs most commonly after fifty years of age,

13 Annales des Maladies de l'Oreille, No. v., 1885, p. 335. It Bulletins et Mémoires de la Société de Chirurgie de Paris, 1886, 658, No. 12.

16 Revue de Laryngologie, 1889 , p. 15 27 Diseases of the Throat, Nose, and Ear, p. 295. sarcoma between ten and twenty years of age. Infiltration and stiffening of the part from which the tumour grows and foul, dirty discharge are both grave symptoms. The family history should always be ascertained. In all cases a microscopic examination should be made, no matter what the macroscopic evidence may be. I would, howerer, agree with $\mathrm{McBride}$ that if the clinical appearances point to malignancy and the microscopic examination to innocence of growth, the former should be trusted rather than the latter. In conclusion, I would reiterate-(1) that true papilloma nasi is a rare disease; (2) that the majority of recorded cases have not been true papillomata; (3) that in many cases it is almost impossible to diagnose macroscopically whether a growth be benign or malignant; and (4) that in every case a thorough microscopic examination should be made of the tumour.

Since writing the above paper I have seen (November, 1894) the patient whose case I have related. The left anterior naris is quite free from any return of the growth, and nasal respiration is quite normal. The septum is healthy, and there is a tiny scar where the pedicle of the papilloma was attached. The rodent alcer on the exterior of the nose has recurred locally.

Queen Anne-street, W.

CASE OF HYDROPHOBIA; NECROPSY. BY W. MITCHELL ROOCROFT, L.R.C.P. KDIN., M.R.C.S. ENG.,

HONORART SURGEON TO THE WIGAN INFIRMARY.

THE following notes are very interesting, as the symptoms were well marked and typical during life and the post-mortem signs were quite pathognomonic of the disease.

A man aged thirty-nine first came to consult me on Oct. 15th, 1894, at 9.30 A.M. He complained of feeling very ill, with stiffness about the back of his neck and inability to sleep. On the previous day at dinner-time he first noticed a slight difficulty in swallowing liquids. This he had attributed to sore-throat, the after-effect of a severe cold from which he had been suffering. On examination there was nothing in the condition of his throat to account for the symptoms. I inquired if he had recently or at any time been bitten or scratched by a dog, but he firmly and persistently denied having at any time received any such injury. On further examination of his limbs and body I discovered a slight scar on the left forearm which was recent. This scar, he stated, was very painful, and he distinctly remembered that he had caused it with a rasty piece of pipe on Sept. 23rd. The tongue was clean and his evacuations normal. The temperature was normal. I ordered him to go home and to go to bed, and prescribed large doses of bromide of potassium and tincture of hyoscyamus to be taken every two hours, and to induce a copious sweating by drinking hot fluids. At 4 P.M. I visited the patient. He said he felt much worse, was cold and shivered; he had not slept, and had not sweated. The temperature was $99 \cdot 4^{\circ} \mathrm{F}$. The respiration was slightly quickened. He had taken three doses of the bromide and hyoscyamus, and drank some warm milk in my presence, though, as he stated, with difficulty. I gave him a hypodermic injection of morphinæ sulphas ( $\frac{1}{2} \mathrm{gr}$.) with atropinæ sulphas $\left(\frac{1}{75} \mathrm{gr}\right.$.), and ordered him into one of my beds in the Wigan Infirmary the same night. Before leaving I again inquired as to any history of a dog bite, but neither the patient nor his relatives had any recollection of any such injury, though they admitted that he had been a dog fancier all his life. He complained of more pain in the scar on his left forearm and had been poulticing it. On the 16th I visited the patient in the Wigan Infirmary and found him much worse. Well-marked symptoms of hydrophobia had developed. His reflexes were exaggerated and there was general hyperæsthesia of the skin and special senses. Any attempt to swallow liquid, even the sight of fluids or hearing liquid poured from one vessel to another, any loud noise, or sudden draught of cold air caused intense clonic spasm of the pharynz and diaphragm. He could swallow solids. The respiration was slightly quickened, but every minute or two he took an involuntary deep sighing inspiration, and there was painful contraction of the diaphragm. The face was flushed, and the head hot, aching, and throbbing; the body was bathed in perspiration; the bowels bad been well moved; 